\title{
ITINERARIS RELIGIOSOS: VOCACIONS I VOCACIONS ALTERNATIVES
}

\author{
Magda Juncosa \\ DEPARTAMENT D'ANTROPOLOGIA SOCIAL I FILOSOFIA \\ UNIVERSITAT ROVIRA I VIRGILI. TARRAGONA.
}

\begin{abstract}
"Sólo el azar y el caos triunfan en ese indeterminado vacío en el que edificamos las mil explicaciones racionales que posibilitan nuestro vivir. Porque la vida del hombre es tal, que necesitamos el engaño y el espejismo para poder soportarla". Cioran.
\end{abstract}

\section{Objecte d'estudi: trajectories individuals}

Si considerem genèricament la religió com una interpretació de la realitat, els grups religiosos amaguen diferents opinions, conviccions i creences per captar aquesta realitat. Cada associació presenta una visió del món analitzada des del seu sistema de creences, el qual només es interpretable des dels paràmetres del propi grup.

Des del punt de vista de l'investigador s'ha d'agafar com a vallid qualsevol codi doctrinari perquè és tan legítim creure en Déu com en els ovnis, creure que la ingesta de carn és contraproduent per l'esperit, tant com que menjar peix cru afavoreix la vinguda d'extraterrestres. Tots els grups religiosos insisteixen a demostrar empíricament el seu propi credo; tot i això, les creences no deixaran de definir-se com prendre per cert quelcom que no ha estat demostrat o comprovat. Es creu en qualsevol cosa que doni resposta o que satisfaci les nostres demandes sobre el sentit de la vida. La religió constitueix un consol davant la impotència de l'individu i respon totes aquelles qüestions que s'escapen a la raó, essent un mecanisme de compensació enfront de les limitacions de l'home. La necessitat d'una esperança per resistir el pes de l'existència converteix allo més increible en acceptable.

A partir d'aquesta interpretació de la religió i d'una documentació basada exclusivament en històries de vida d'individus que formen o que han format part d'una associació de caire religiós, i mitjançant una anàlisi comparativa, es quiestionarà l'existència d'un "perfil d'individu religiós" o de vocació religiosa.

La trajectòria individual pren una importància fonamental davant el contingut del credo $\mathrm{i}$ de les pràctiques que aquest comporta, aspectes que deixarem en un pla secundari tot i que serà pràcticament impossible no fer-ne referència. També es passaran per alt tots els tòpics que comporta parlar de sectes com la captació o el rentat de cervell entre altres, intentant aportar la màxima objectivitat.

L'important és l'individu i el perquè ingressa en un grup específic, quina motivació l'ha impulsat. L'objectiu d'aquest treball és conèixer quina ha estat la trajectòria vital que ha establert la connexió entre l'individu i el grup.

S'ha disposat de diverses històries de vida: des d'individus que han tingut relació amb grups religiosos denominats pejorativament sectes, fins a grups que s'inclouen en la religió legítima 0 oficial. S'ha posat a un mateix nivell un Hare Krisna -religiós considerat il-lícit per la societat-, un Testimoni de Jehovà -individu aprovat, però situat fora de la norma- $\mathrm{i}$ un ex-carmelita o membre 
de la religió convencional, el qual actua des dels cànons més oficials. A partir d'aquestes diferenciacions de legitimitat social s'han intentat extreure els punts que tenen en comú $i$ en particular uns $\mathrm{i}$ altres.

Per a una millor il-lustració hem cregut necessari mostrar una síntesi d'algunes històries de vida d'individus que han estat o encara són membres d'un grup religiós i que, com hem dit, s'han utilitzat com a marc de referència i punt de partida. A l'annex hem transcrit dotze històries de vida, seleccionades d'una mostra més àmplia utilitzada en l'estudi, hem resumit les més significatives sense deixar de tenir en compte la diversitat des del punt de vista de la legitimitat.

2. Estudi comparatiu de les històries de vida: perfil pre-sectari de l'individu o trajectòria vital anterior a l'ingrés

La pregunta si la vida prèvia al grup té relació amb l'ingrés és el punt fonamental per abordar aquest estudi.

Tractarem d'extreure quines similituds i quines diferències existeixen en les trajectòries vitals d'aquests membres, si hi ha punts en comú, si existeixen factors de risc o vulnerabilitat, com crisis personals, estructura patologica de la personalitat o personalitats cercadores, o si aquests factors apareixen en tots els casos o simplement són anecdòtics.

Possiblement tots els individus disposen de raons apriorístiques que els porten a desenvolupar una determinada activitat. Llavors els membres de qualsevol grup religiós disposen de les suficients motivacions personals que poden afavorir l'ingrés en el grup. Aquestes motivacions poden ésser espirituals, terapètiques o d'un altre caire, o també poden no existir i aparèixer després de conèixer el grup.

Si llegim amb un mínim de deteniment les biografies o històries de vida que hem transcrit de forma lliure, de seguida salten a la vista certs trets o característiques que es presenten d'una manera o d'una altra, més aviat o més tard, dites o suggerides, a totes o a quasi totes elles. N'hi ha unes com la famflia catòlica, la procedència migratòria o l'educació a col-legis religiosos, per esmentar-ne algunes, que tot i ser redundants no es poden considerar indicadores d'un determinat perfil perquè són trets característics d'una època que es presenten en gran part de la poblacio; tanmateix n'existeixen d'altres, si es vol, més indefinides, que segons Alvaro Rodríguez són més determinants a l'hora de configurar un perfil.

Hem dit que aquelles característiques quantitatives -que apareixen en la majoria dels membres- no revesteixen importància i les de caràcter qualitatiu, que són enumerades per Alvaro Rodríguez com a factors de predisposició i que accentuen la vulnerabilitat dels individus a l'acció dels grups religiosos, són les segũents:

al El període d'adolescència-joventut.

b/ Alguns trets neuròtics de la personalitat: tendència a la solitud i a la depressió, dificultat en la comunicació $\mathrm{i}$ immaduresa afectiva, angoixa, confusió $\mathrm{i}$ inseguretat, dependència $\mathrm{i}$ baixa autoestima, idealisme ingenu, credulitat i baixa tolerància a l'ambigüitat.

d Dificultats d'adaptació social.

¿ El desig de profundització espiritual.

Un sistema familiar disfuncional.

il Altres factors puntuals: droga, diners, parella, inseguretat, etc. (Rodríguez, 1993:89).

Havent vist aquests determinants psico-socials, queda definida una "personalitat presectària"? Quines serien les característiques que la conformarien? Citant West (1988), Rodríguez dirma que no es pot parlar d'un únic perfil sinó d'una amalgama de tendències o factors de predisposició, en contraposició al que fins fa poc es pensava, "que los sujetos reclutados por las 
sectas destructivas padecen ya de antemano algún desajuste en su personalidad que justifica esa vinculación" (Rodríguez, Op.cit., 89).

Es molt difícil constatar l'existència d'un perfil pre-sectari. $\mathrm{Hi}$ ha una sèrie de característiques socials i psicologiques que no s'ajusten a un model $\mathrm{i}$ un individu pot entrar en un grup religiós sense que s'acompleixi cap dels factors citats anteriorment. Rodríguez fa esment d'uns elements de risc que, si bé alguns apareixen a les biografies dels membres, no són significatius ni especifics de tots els individus ni només de grups religiosos. Són factors de vulnerabilitat que poden generar conductes estigmatitzants, però no necessàriament, i que poden conduir a qualsevol apartat de la societat.

No es pot parlar d'un perfil específic o d'una personalitat típica que caracteritzi els possibles adeptes, però alguns autors parlen d'un elevat sentit d'insatisfacció en les vides dels individus abans de sintonitzar amb el grup religiós. La nostra casuística confirma, si no aquesta insatisfacció o infelicitat, sí un sentiment -present en alguns dels membres- d'inquietud i preocupació per algun tema en concret, de manca d'alguna cosa, de necessitat d'un sentit per viure, motivador de la recerca espiritual.

Tot i que molts estudiosos han corroborat que tothom és vulnerable i té les mateixes possibilitats d'entrar en un grup religiós si és connectat en el moment adequat, nosaltres creiem que no és aixi: aquest moment no determina l'ingrés en una secta i no tothom és susceptible d'ingressarhi ni té les mateixes probabilitats.

Però el que cobra transcendència és saber per què un individu s'inquieta o es neguiteja i un altre no. En aquí es troben factors entrecreuats: els exdgens, provocats per la influència de la famflia, dels amics, de la societat i de l'entorn en general; i els endogens, propis de la personalitat del possible candidat. Alguns autors (Clark i cols., 1981) han arribat a parlar d'una societat presectària provocada per la manca de valors estables i generadora de demandes espirituals.

Pero, què hi diuen els mateixos interessats quan necessiten explicitar la seva pertinença al grup? Agafant l'exemple de Gnosis, s'observen individus que han entrat per diverses vies que convergeixen en un centre comú que es podria denominar el dels "misteris acientífics": l'astrologia, l'esoterisme, l'ocultisme, la vida interplanetaria, etc. Els temes a tractar sedueixen les persones d'ambdós sexes i de totes les edats, independentment que siguin o no catolics. Per altra banda, els Testimonis de Jehovà, com altres membres de grups religiosos, troben una resposta satisfactoria a l'angoixa vital que comporta saber-se mortal. Així ho tradueix un TJ: "El saber que nuestra vida st tiene proposito y realmente es algo maravilloso. Saber que en un futuro este sistema de cosas va a ser reemplazado por un nuevo orden es una satisfacción tan grande (...), restaurar la humanidad, eso es lo que quiere Dios. (...) realmente esa recompensa es la mayor que una persona puede esperar: vivir para siempre. (...), el ser humano necesita tener alguien, alguien que nos gufe, alguien que nos dirija". La majoria de membres dels diferents grups afirmen haver trobat allo que estaven buscant o esperant, ara coneixen la veritat i tenen respostes per a tot.

Funcionalment tots els grups, siguin majoritaris o minoritaris, representen el paper que sempre ha fet la religió, possiblement un xic actualitzat, que és aportar respostes existencials a qüestions on la ciència no ha arribat: la vida després de la mort, la vida en altres planetes o el sentit de l'existència, entre altres. Es pot dir que el que no pot respondre la rao, ho contesta l'emoció (el credo d'algun d'aquests grups, a més de donar la resposta tedrica, també dóna la solució pràctica. I sempre s'acaba solucionant l'enigma que des de sempre ha preocupat l'home: la mort).

Acabem de veure que la resposta que aporten els diferents grups és idèntica. Pot variar la forma, però l'efecte que produeix en els membres és el mateix: una acció terapèutica enfront dels problemes actuals $\mathrm{i}$ els dubtes de sempre.

Deixant a banda les diferències que com hem dit són predominantment temporals i que repassarem en finalitzar aquesta primera part, remarcarem algunes de les similituds que han aparegut a les histories de vida i que consten com a factors de predisposició en A. Rodriguez: 
a/ El contacte amb el món de la droga, previ a l'entrada en el grup religiós, és un element comú en alguns membres, present a partir de l'època contracultural i un dels seus elements definitoris. Aquest és viscut com una recerca, com una experiència. Es pot pensar en un cert paral-lelisme entre droga i secta, ja que en un determinat moment historic ambdues van desenvolupar una mateixa funcio: actuar com a alternatives entre la joventut davant un món percebut com a reaccionari. Es buscava entendre la vida per mitjà dels al-lucinogens o de la religió. Tant la droga com la secta són possibles respostes a idèntiques preguntes formulades per "personalitats cercadores". Un membre de Brahma Kumaris ens explica: "Tomábamos drogas como experiencia, LSD, cocaína, heroína, probé unos hongos que había en la montaña (...) no tenía miedo. He hecho pruebas yo solo y amigos míos observándome a ver qué pasaba. Era como una búsqueda".

Aquests individus pre-sectaris que han tingut relació amb la droga pertanyen a grups religiosos no legitimats com Brahma Kumaris, Hare Krisna o Gnosis, o mig legitimats, com Testimonis de Jehovà, i han tingut una trajectòria vital de recerca constant. No apareix cap membre de la religió oficial que hagi tingut una relació d'aquest tipus ${ }^{1}$.

Rodríguez assenyala la droga com un factor de predisposició que converteix l'individu més vulnerable i que és extrapolable a qualsevol altra influència, a més de la provocada pels grups religiosos.

b/ Les inclinacions espirituals es troben presents en membres de qualsevol grup religiós, encara que no en tots els membres. Elements relativament indefinits, com el sentit de religiositat, la necessitat de creure, la vocació, etc., apareixen, per exemple, en els Testimonis de Jehovà, en els Hare Krisna $\mathrm{i}$ en les monges benedictines. Pensem que aquests factors presenten la religiositat com una conducta natural i innata que no necessita ésser explicitada.

Una Testimoni de Jehovà ens diu: "Yo si que quería ir a misa (...) yo he tenido siempre un sentido alto religioso (...) yo tenía una necesidad de hablar con Dios", la inclinació espiritual es percep com quelcom intern inherent a l'individu i imprescindible. Un ex-membre de Moon experimenta una vivència similar: "Hay una búsqueda individual(...) es algo innato, nadie ha demostrado que todo eso sea una invención, no se sabe (...) de donde venimos y adónde vamos".

L'element sobrenatural pot incitar a la conversió, sigui aquest un sentiment intern inexplicable, com el que va experimentar aquesta monja benedictina, "a l'arribar per primera vegada a Vallbona vaig notar una tranquil-litat $i$ una pau fins aleshores desconegudes, em sentia molt bé, en una serenitat indescriptible", o aquest Hare Krisna que, en nombroses ocasions, fa referència a emocions d'àmbit metafísic, "me acuerdo que una vez estaban cantando y escuché el mantra Hare Krisna y me impactó mucho. Fue una cosa (...), fue un contacto muy fuerte (...). El primer contacto con el kirtan era una cosa que te entra, que tú dices aqui hay algo y ni tan siquiera sabes el significado de la palabra del mantra, pero era una cosa que llamaba (...) lo mismo que las pinturas de las gopis". En el mateix nivell es troben els miracles o visions experimentades per un membre de Raschimura i que el portaran a reafirmar la confiança en el grup, "habla una chica que tenía esclerosis múltiple, que no se podía mover, y el último día se levanto. Eso yo lo vi, se montó una situación de trance colectivo, entonces fue cuando vi al tio levitando, brillante, plateado y la chica se levanto". A Gnosis, aquest element sobrenatural també apareix en els viatges astrals $\mathrm{i}$ en la creença en el poder de la ment que mostren als seus membres.

Amb aquests darrers exemples volem constatar que l'element transcendent, que apareix en membres de diferents grups religiosos, legitimats o no, intenta donar credibilitat i reforça el sentiment religiós. Aquesta variable, ja sigui teòrico-metafísica o pràctico-miraculosa, que transcendeix a allo terrenal, és un mecanisme de conversió molt eficaç: "després de sentir i experimentar una cosa tan forta ja ho veus tot clar, ja saps el camí que has de seguir a la vida",

${ }^{1}$ Aquesta esdevindria una diferència entre els grups oficials i els que no ho són: la droga, tan il.lícita com la secta, 00 sol formar part de la historia de vida de cap membre catòlic. 
ens diuen diferents individus amb altres paraules. Alguns experimentaran l'espiritualitat abans de conèixer el grup i altres ho faran després d'establir-hi contacte, com per exemple un ex-membre de Raschimura que va començar assistint a classes de ioga i "a partir de aht te explicaba (el mestre), aparte de darte la clase normal, la filosofia de por qué el yoga (...) o sea, la parte espiritual de aquello. (...) Entonces empiezas a entrar un poco en el campo metafisico (...) te plantean el dilema de si existe Dios".

c/ La predisposició temperamental o caracteriologica a l'hora d'entrar en un grup religiós és fatent en alguns individus, manifestant-se en el fet que aquests poden patir algunes contrarietats, normals per a la majoria de la gent, però que a ells els fan ser més susceptibles.

Als adolescents $\mathrm{i}$ joves, se'ls atribueix un caràcter vulnerable alhora que idealista. Tots els casos que hem tractat són individus que van ingressar en el grup essent joves, a excepció d'alguns membres de Gnosis. Quan deixen d'ésser joves, alguns abandonen el grup, però no per aquest fet, sinó per altres factors que poden no tenir res a veure amb l'edat; altres membres hi continuen de per vida.

En segon lloc, persones que travessen una fase depressiva o passen per un mal moment, sigui professional, de salut, familiar o amorós, poden ésser susceptibles d'entrar en un grup religiós. Tenim el cas d'un membre de Moon que diu: "en el momento que me encontré con esta gente estaba un poco deprimido, no veía el mundo muy claro (...) en esos momentos necesitaba comprensión, amistad y compañerismo". O un membre d'AGEACAC, el qual passava per un mal tràngol: "la chica con la que salía murió de un ataque de asma, entonces esto fue un golpe bastante duro para mi, entonces esto que quieres dar la vuelta a tu mundo".

Els subjectes de caràcter altruista poden ser més vulnerables a l'acció dels grups religiosos; prenent un exemple, que creiem molt frequient, podem referir-nos a un membre d'AGEACAC, que en deixar el grup se'n va anar de col-laborador amb la Creu Roja i amb un grup infantil de la parròquia; també algunes monges benedictines, abans de realitzar els vots, havien participat voluntàriament en accions humanitàries. Aquest tret caracteriologic té una estreta relació amb un altre element que també es troba present en alguns dels individus: l'interès per la política. Un Testimoni de Jehovà ens diu: "Yo me metl de lleno porque tengo un alto sentido de la justicia, no soporto la injusticia. No es que me defina con una idea propia (...) yo ante la injusticia me rebelo (...). Yo he sido una persona que he intentado siempre buscar algo, lo he intentado de diferentes maneras y pensaba que en la política lo encontraría". Alguns membres de Gnosis també havien militat en sindicats polítics.

Però a més d'aquests col-lectius tan habituals en la literatura sectària i que no són significatius quantitativament, hi ha molts altres individus que no responen a cap d'aquestes particularitats; van a parar a la religió moguts per altres desencadenants, com per exemple el simple fet de buscar no se sap què més enllà d'allò real o, si es vol, individus amb ànsia de veritat.

Havent vist característiques comunes en alguns membres (l'espiritualitat, la política, etc.), hem de fer referència obligada al moment històric, ja que aquest pot actuar de determinant en alguns dels elements referits. La socialització que apareix en cada moment generarà un o altre tipus de religiositat, deixant el factor psicologic en un pla secundari.

Unicament en la predisposició que apareix a cada època trobarem la diferència entre els membres legítims $\mathrm{i}$ els menys legítims. Es poden observar tres èpoques molt diferenciades amb la seva corresponent influència sòcio-històrica: la postguerra (dècada dels quaranta i cinquanta), la contracultura (dècada dels seixanta i setanta) i l' actual (dècada dels vuitanta i noranta). A la primera època, és la familia qui exercirà més influència sobre el possible candidat; la predisposició vindrà donada per la tradició, la qual afavorirà l'ingrés en un grup legitimat, inculcant al nen, des de petit, els principis del catolicisme i educant-lo (tant la familia com l'escola) per desenvolupar 
una tasca religiosa ${ }^{2}$.

El nen -possible membre- no decideix: és la societat qui ho fa. Es una època en què l'Església té prestigi i la religió serveix d'excusa per arribar a altres fites. Vegem l'exemple d'un salesià: "Jo, a més d'anar a l'escola, feia de pastor amb el pare. A l'escola hi anava quan podia, però un bon dia va passar un senyor d'aquells, un reclutador vocacional $i$ em va entusiasmar perquè em va semblar que podria ser una sortida cap a uns estudis. Ells eren mestres". D'aquesta manera, alhora que se solucionava un problema economic familiar, estava ben vist socialment.

A la segona època, la denominada contracultura, promoguda per una elit intel-lectual i amplificada per grups musicals i una certa literatura, es rebel-la contra l'establert i, per tant, també contra la religió dominant, però no contra la religiositat, la qual conduirà els joves a formar part d'alternatives a la religió oficial vingudes d'Orient. Una ex-membre de Siddha Ioga ens diu: "Era moda pertenecer a un grupo de éstos, era la época de los progres, del rollo politico y esto era contracultural total. El rollo era ir en contra y todo medio mezclado con las drogas".

Els joves estan en desacord amb la societat $i$ es formen grups que lluiten per una causa, per transformar les convencions socials. Aquells que opten per la religió, escullen la banda passiva, s'automarginen donant l'esquena a la societat $\mathrm{i}$ vivint de manera alternativa.

Per acabar, actualment no es troba un model tan estipulat com a les èpoques precedents, encara que s'observa una predisposició més individual: hom s'integra en un grup per una quiestió concreta, atès que existeixen grups per a qualsevol tipus de dubte espiritual o d'un altre caire. Un individu amb un problema estara més predisposat a buscar una solució, que pot trobar en un grup religiós, que un altre que no tingui res a solucionar. Hi ha grups que solucionen problemes físics o psicologics, entre els quals podríem esmentar Cienciologia, el Moviment Gndstic Universal, Raschimura, etc. Són grups eclèctics on es barregen tots aquells temes vinculats amb l'acientificitat (religió, ovnis, astrologia, tarot, etc.) i amb l'orientalisme (acupuntura, ioga, meditació, etc.). Tot i que hi ha alguns grups que estan disposats a canviar la societat, observem que la tonica general és individualista. Actualment hi ha diferents vies per canalitzar idèntiques angoixes.

\section{Oferta i demanda}

Aparentment tot el descrit en l'apartat anterior hauria de conduir-nos a afavorir el primer contacte; tanmateix és necessari aturar-se en diferents qũestions: per què hi ha un primer contacte? Es voluntari o casual, és a dir, buscat o trobat? A què és degut? I on es produeix? Ens referim a la responsabilitat del primer encontre: és l'individu qui cerca el grup per resoldre uns problemes o és el grup qui crea uns dubtes per després oferir-ne la solucio? Veurem que existeixen diferents possibilitats.

El lloc on es produeix el primer contacte és intranscendent, pot ésser al carrer, mitjançant un conegut, en una conferència, etc. Al carrer trobem la comunicació oral si hom es topa o busca el grup, i la comunicació visual si hom veu un anunci del grup per assistir, per exemple, a unes xerrades o conferències. De la mateixa manera, el sistema de xarxes socials, del conegut o de "Tamic m'ha dit..." funciona amb molta freqũència.

La primera relació pot consistir en la venda d'un llibre, la realització d'un test o una classe de qualsevol tema de caracter resolutiu. Per exemple, si hom està interessat per l'astrologia $i$ veu un anunci on s'ofereixen classes gratuittes, hi ha la possibilitat que hi assisteixi. Aquest esquema es reprodueix en molts membres de Gnosis, els quals reben la primera informació del tipus "vi un

${ }^{2}$ En aquest moment no existien grups equiparables a les actuals sectes, si més no existien persones que desenvolupaven algunes funcions que avui dia es troben en mans de grups sectaris, com funcions terapèutiques per demandes de salut. Ens referim a remeieres o curanderes, solien ser dones, que curaven determinades malalties. Tanmateix aquestes estaven legitimades socialment. 
anuncio por la calle".

L'Associació Gnòstica Universal i altres grups gnòstics fan publicitat mitjançant rètols on anuncien classes d'esoterisme, ocultisme, cabala, extraterrestres, de millora personal $\mathrm{i}$ altres temes d'aquesta mena. L'oferta d'aquesta i d'altres associacions és arribar allà on la ciència no ha arribat, donar resposta a allo desconegut $\mathrm{i}$ ajudar a l'autoconeixement. Un conjunt molt suculent $\mathrm{i}$ actualment amb molta demanda.

Se sap que els Testimonis de Jehovà es donen a conèixer realitzant visites programades a cases particulars, però a les nostres entrevistes no apareix cap cas amb aquesta característica. Disposem de primers contactes més o menys casuals o espontanis que funcionen pel "boca a boca", a través de xarxes socials. També hi ha membres que van tenir la primera relació mitjançant un llibre que va arribar a les seves mans i a partir d'aquf comencen a investigar.

En el primer contacte hi juga un paper fonamental el factor atzar. Conèixer un grup o un altre, $\mathrm{o}$ un individu concret $\mathrm{o}$ un altre, fonamentalment es deu a la casualitat. El que continua després ja ho determina el possible convers. Si el contacte és buscat, el factor atzar passa a un segon terme.

Altres associacions es donen a conèixer oferint consultes o classes terapèutiques. Són centres on es fa ioga, acupuntura, dietètica, medicina naturista, relaxacio, etc. Es aquí on els futurs membres estableixen el primer contacte. En general es tracta d'individus amb algun problema que acudeixen al centre en busca d'ajuda $\mathrm{i}$ aquest els aporta unes pràctiques que més endavant solen convertir-se en teories. Com a il-lustració d'aquest fet, trobem grups com Rachimura, Brahma Kumaris, Siddha Ioga, Fundació Guasch o Sahaja Ioga. El possible adepte hi acudeix per un problema puntual, per exemple d'estrés, i acaba plantejant-se el sentit de l'existència. En el cas de Rachimura, veiem un noi que intenta buscar solució a una manca de concentració mitjançant el ioga, però a mesura que es va introduint en aquesta tècnica el grup li aporta noves qũestions $i$, a la vegada li'n dóna la sortida. Hem de dir que, si bé són nombroses les persones que busquen els serveis d'aquests centres (moltes d'elles provenen de la medicina convencional, la qual no ha pogut resoldre el seu problema i cerquen una alternativa), són ben poques les que acaben convertint-se al seu credo.

Altres individus han tingut el primer contacte al carrer, en parades provisionals o amb venedors de llibres. Un membre de Moon així ho descriu: "fue un encuentro fortuito, por la calle. No fue una inquietud que tenia yo (...), yo en esos momentos necesitaba, bueno, en realidad todos necesitamos comprensión y alguien que te escuche (...). Todo lo que fuera religión era secundario". Per a ell va ésser un contacte casual, no buscat, però favorable a causa del moment que estava travessant.

Les histories de vida de membres de grups legitimats coincideixen en el fet que han tingut el primer contacte de la mà del "reclutador vocacional". Actualment aquesta figura ha desaparegut correspon a una època determinada a què ja hem fet referència-, però avui dia existeixen altres aparells que gesten possibles vocacions: els catequistes, els esplais catolics o les escoles religioses, a més d'algunes institucions dedicades a l'ajuda humanitària. Les circumstàncies que envolten el primer encontre en religions convencionals formen part del mecanisme enculturador de la nostra societat. El misoneisme, a nivell religiós, queda palès i la tradició en justifica la legitimitat: no es pot pensar en una escola especifica per als Nens de Déu ni per als nens de cap altre grup religiós, però sí per a tots aquells grups relacionats amb l'oficialitat. D'aquesta manera existeixen escoles amb un règim intern propi del grup més coercitiu i que actuen dintre de la normativa. La historia de vida del salesià així ho confirma: "no tenies ni temps de pensar en res, perquè ja t'ho portaven tot programat (...) I les vacances també les feiem alla, no marxdvem a casa. Podíem anar a veure els pares una vegada cada dos anys $i$ durant vuit dies". Al catolicisme li ha estat permès i li esta permès l'accés a les escoles. Pensem, per exemple, en la figura del -mencionat anteriormentreclutador vocacional (i també del missioner) que predicava pels pobles i encenia entre els nens la flama del sentir-se escollit. Avui dia aquestes dues figures s'han substituït per les tan prestigiades 
escoles catoliques on poden gerninar futurs membres d'aquests col-lectius.

Una altra forma d'entrar en contacte es troba en la parcel-la espiritual: la "crida de Déu". Algunes monges benedictines ens han dit que elles no van anar a buscar a Déu, sinó que és Déu qui es presenta a elles, qui les crida. Trobem el mateix plantejament en la biografia d'un Hare Krisna, el qual fa referència a "una cosa que me llamaba, una cosa muy fuerte".

Els membres de 1'Opus Dei efectuen contactes a escoles i residències. Aquests disposen d'una complexa xarxa d'immobles on es donen a conèixer. Una noia ens deia: "Jo he entrat per uns capellans que em van dir que (...) tenien uns pisos on estaven tot de noies de Barcelona i que s'estudiava moltissim (...). A mi m'havien anat malament els estudis $i$ els meus pares van decidir que hi anés".

Hem vist que hi ha diferents possibilitats: en uns casos és el subjecte qui cerca el grup, com per exemple en Brahma Kumaris, Gnosis o Raschimura; en altres és el grup qui estableix el primer contacte, com en l'exemple de Moon. També es pot donar que el grup i el subjecte coincideixin a la vegada. En tot cas, però, sempre és fonamental l'acció d'ambdues parts, és a dir, l'interès no pot venir només d'un dels implicats sinó que les dues bandes interactuen per afavorir l'empatia.

Si el primer encontre ha estat satisfactori pot conduir a contactes posteriors: si el grup ha interessat o ha encès la curiositat al neòfit, aquest repetirà la visita.

Les accions que es desenvolupen en un primer contacte s'acostumen a repetir a la fase de pre-integració. En els gnòstics, per exemple, el primer encontre és una reunió o classe a la qual sol assistir força públic. Les classes es repetiran un cop per setmana. Conforme avancen les setmanes, el públic va disminuint i així molts dels possibles membres desapareixen pel camí. Aquells que continuen interessats en la temàtica realitzen proves d'accés de nivell, passant a cursos més elevats i iniciant-se en les pràctiques: meditacions, oracions, invocacions, excursions, etc. També se'ls explica quines obligacions i exigències comporta la pertinença al grup, a les quals s'aniran adaptant amb el temps.

Però vegem, amb un exemple, què fa que continuï l'interès dels individus, a part dels temes que es tracten. Una dona de 36 anys afirma que Gnosis li va donar molta seguretat en ella mateixa, la va ajudar a acceptar-se: "Gnosis (...) es saber siempre quién eres y donde estds. Y no somos conscientes (...). La historia de Gnosis está en reencontrar la esencia, en ser tú (...) todo lo que se ha ido afiadiendo a tu esencia es lo que has de ir eliminando.(...) Invocamos a los elementos naturales, yo al fuego le pido que haga un círculo en mi vivienda y que no deje pasar nada de fuera."

Després de veure una primera constant, que podríem denominar foment de l'autoestima, mitjançant la qual s'aconsegueix que la persona se senti important $\mathrm{i}$ necessària, hi ha un segon factor que actua directament relacionat amb aquest: és el sentiment d'exclusivitat. Sentir-se especial o escollit és una altra particularitat que es dóna abans del possible ingrés en el grup i que pot actuar de darrer esglaó d'entrada. Aquest sentiment pot venir donat per la revelació d'un secret " (...) que la mayoria desconoce y tú estás capacitado para conocer", com ens diu un ex-membre de Moon. Creure que hom té poders ocults extraordinaris que, amb el temps, se li desenvoluparan és un altre factor per mantenir viu l'interès: "(...) quan ell -el conferenciant de Gnosis- em deia que podia ser més que els altres, que podia dominar a la gent (...), que estava capacitada $i$ que d'aqui a poc temps ja podria entrar a formar part del que (...) ells seleccionaven (...). Perque no tothom estava capacitat (...). A mi el que em cridava l'atenció és que pensava: bé, si aquesta gent més endavant em donem la clau pel poder $i$ per poder dominar la ment (...). Aquesta cosa era el que em feia estar all" ". Ens diu un ex-membre de Gnosis.

Un ex-membre de Raschimura, a qui van convèncer una sèrie de pràctiques "miraculoses" del seu mestre, també es troba a l'espera de la revelació de la veritat: "El maestro me dijo que él y a me habla dado el conocimiento, que siguiera sus ensefianzas y todo se arreglaria. (...) Entonces yo me planteé a ver si estaba dejando escapar la oportunidad de mi vida y si realmente el tó éste era el maestro para esta época." 
A biografies de membres de l'Opus Dei també apareixen aquestes connotacions quan els pares espirituals diuen als seus possibles deixebles que aquests tenen vocacio: aix se sentin triats d'entre la majoria.

Una altra constant directament relacionada amb les anteriors és tenir esperança o donar sentit a la vida. Els Testimonis de Jehovà disposen d'una esperança a llarg termini. Els contactes posteriors consisteixen en l'estudi $i$ aprofundiment de la Bíblia, la qual conté la veritat. En els escrits descobreixen l'esperança, la raó de viure. Aquest col-lectiu disposa de respostes per a qualsevol pregunta, tenen solució per la qũestió més inversemblant. Molts dels seus arguments acorden un caire de cientificitat amb demostracions mil-leraristes i numerologiques i utilitzant termes del tipus "investigar", ja que ells "investiguen en la Biblia per trobar la veritat i l'origen de la vida". També tenen solucionat el problema de la mort i esperen una vida millor on regni la pau i la felicitat.

Rafel, Testimoni de Jehovà de 33 anys, viu amb una esperança que dóna sentit a la seva vida, la que "Déu vigila el que passa a la Terra i destruird els que oprimeixen, transformant la Terra en un paradís (...). Això anima la gent a tenir fe". Déu apareix com un superheroi impartidor de justícia.

Després d'esmentar algunes de les possibles constants que fan mantenir la confiança en un grup religiós, veurem que aquestes porten afegides una sèrie de prescripcions, les quals s'ampliaran a mesura que la implicació augmenti. Els contactes es faran cada cop més freqüents, creences i pràctiques es van incorporant a la vida diària del subjecte: els possibles membres realitzen les pràctiques grupals a les seves cases, en solitari. Es a dir, es viu "allà" amb la filosofia d'"aquí" i així el subjecte introdueix la filosofia del grup a la seva quotidianeïtat. A més dels contactes regulats, hi ha contactes més intensius sota la forma d'excursions o sortides, cursos, convivències, etc.

Aquells membres que van començar per la teoria, en els contactes posteriors obtenen la pràctica i viceversa. Es a dir, si els gnòstics comencen amb classes tedriques, a mesura que avancen les classes es convertiran en pràctiques, ja siguin de meditació o de viatges astrals. I si es comença amb classes pràctiques com, per exemple, Raschimura, que s'inicia amb ioga, es continua el curs explicitant la filosofia.

Si parlem exclusivament de grups legitimats, s'observen uns contactes posteriors, previs a la integració, molt estructurats. A partir dels contactes inicials es canvia radicalment de vida, ja que en certa manera aquest implica pertinença (pensem en el nen que entrava en un seminari o en la monja que ingressa en un convent). L'individu passa a viure amb el grup $\mathrm{i}$ a portar una vida farcida d'obligacions, no viscudes com a tals per l'interessat, és clar; el mateix passa amb totes les institucions comunitaries. Tot $\mathrm{i}$ que hi ha una fase de preparació, com en tots els grups abans de la total integració, en els grups que viuen en comunitat resultarà molt més exigent comparada amb la resta d'institucions.

En els contactes posteriors es comença a delimitar el factor espàcio-temporal, el qual varia segons el grup, establint-se una diferenciació: les institucions comunitaries, siguin legitimades o no, tenen el temps i l'espai molt més delimitat i estipulat -suposem que per pura adaptació- que aquelles que no viuen en comunitat. El temps d'integració és molt diferent d'una institució a una altra: en els benedictins transcorren de cinc a deu anys abans de la total integració, mentre que en els Testimonis de Jehovà aquesta fase prèvia pot durar alguns mesos o un any. En algunes entitats l'espai de culte varia depenent del nivell d'integració. En els gnòstics, per exemple, existeix un espai per a neòfits, que és l'aula on es fa la classe i un per a iniciats, que és la sala de meditació. Els Hare Krisna també tenen estipulat l'espai, l'accés a alguns llocs queda diferenciat segons sexes i segons l'estat civil. Així, temps i espai actuen de mecanismes integradors dins el grup de manera que estan completament ritualitzats. 


\section{Nivells d'integració}

De tots els individus que han tingut relació amb una institució religiosa, són molt pocs els que han arribat a una plena integració. La majoria són membres flotants i provisionals que mai passaran la barrera endins, que tindran contactes esporàdics o relacions més o menys amistoses amb el grup. Aquests membres que pul-lulen al voltant mai no acabaran d'establir un compromís definitiu, pero sí poden tenir certes obligacions i, sense integrar-s'hi del tot, considerar-se'n militants.

Dels membres de l'associació gnòstica que hem utilitzat de testimonis, per exemple, cap ha arribat a concentrar tota la seva vida en el cos doctrinari que defensa. Són persones que es reuneixen puntualment unes hores per setmana i que senzillament són simpatitzants del credo o de la praxi gnostica.

A la integració s'hi arriba havent superat uns nivells establerts; cada associació en disposa d'uns de propis, tot i que formalment s'assemblen. Mitjançant una cerimonia d'entrada hom queda integrat en la institució, encara que és molt difícil delimitar la integració d'aquells membres que, tot $\mathbf{i}$ considerar-se de l'associació, no són "membres de ple dret". Però vegem quins passos se segueixen abans d'arribar al ritu iniciàtic que implicarà la plena integració. Trobem conductes integradores que són el conjunt d'accions que condueixen a la inserció o enculturació a l'entitat. Podem distingir-ne de dos tipus: les formals o explícites, actes establerts i reglats pel grup, com pot ésser un examen teòric, que portaran a l'individu a canviar d'estadi; i uns actes més arbitraris alguns d'ells mencionats en l'apartat anterior, ja que és molt difícil establir on comença la integració-, mitjançant els quals l'individu introjecta les normes del grup a la seva vida quotidiana. Aquests darrers actuen d'una manera més irregular i no tan pautada, fent que l'individu introdueixi les pràctiques del grup a la seva vida privada: meditacions, reflexions, cants o viatges astrals són practicats fora de l'ambient grupal. Els gnòstics, els hares, els TJ, els baha'is o els bramis entren les ensenyances a les seves cases mitjançant préstecs o venda de llibres. Hi ha altres actes espontanis d'integració tals com l'adquisició de fetitxes o amulets característics de la institució. Tots els membres de Brahma Kumaris porten el mateix anell i els gndstics, la mateixa medalla. En alguns casos la indumentària o vestimenta també disposa d'una forta càrrega simbòlica. Solen ésser les associacions comunitaries, legitimades o no, les que més reglat tenen aquest aspecte. El mateix passa en l'àmbit de l'alimentació i de la sexualitat; tots aquests actes informals cobren molta transcendència ja que l'individu pot començar a sentir-se identificat amb el grup sense que aquest estigui present.

De tots els individus que han tingut algun tipus de contacte, els que consoliden el ritual iniciàtic són una minoria, ja que uns han abandonat el grup per manca d'interès i d'altres han estat refusats. Aquest ritu implica la plena integració i consisteix en una cerimònia de canvi d'estatus: una signatura, una ablució, etc. Si es pren, per exemple, la decisió d'ésser TJ, aquesta queda simbolitzada pel baptisme. Amb aquest ritual es passa a ésser "súbdit del govern de Jehovà o esclau de Déu". Per arribar fins aqui, anteriorment s'haurà d'haver efectuat "una millora de personalitat i estar disposat a sortir a predicar."

Entre els Hare Krisna, abans de la total integració, ha d'haver-hi una adaptació als habits alimentaris i sexuals del grup. Es rep una primera iniciació que comporta un canvi de nom', la realització d'uns vots, l'acompliment d'uns principis i la revelació d'un mantra. Tot plegat simbolitza ésser membre de ple dret. Més endavant es rebrà una segona iniciació amb la qual es reafirmarà el compromís. L'Opus Dei no requereix cap cerimònia específica per a la incorporació. El canvi d'estat es manifesta mitjançant una declaració formal: una carta on es demana l'admissió. A la Fe Baha'i la integració es fa palesa a través d'una signatura amb la qual hom queda convertit

\footnotetext{
${ }^{3}$ Raschimura usa aquesta mateixa pràctica: el canvi de nom que dóna constància d'un canvi d'estat.
} 
en baha'i.

Altres agrupacions, com Brahma Kumaris, no exigeixen un ritual concret per entrar a formar part de l'orde, però sí una continuittat en l'assistència a les classes que cada cop seran més frequients $\mathrm{i}$ intenses. El procés identificador suposarà l'adaptacio als paràmetres del grup, tant teorics com pràctics. Quan el grup comprovi que els membres han traduït les pràctiques a la seva vida diària, aquests seran acceptats.

Salesians i carmelites, entre altres ordes legitimats, disposen d'un procés integrador de llarga durada. Recordem el cas d'un membre de la Salle que va iniciar-se en el seminari als 11 anys $\mathrm{i}$ hi va ingressar plenament als 26 , pronunciant els vots perpetus; o d'un membre carmelita que va començar als 9 anys, als 19 fa el noviciat $i$ uns anys després realitza els vots ${ }^{4}$ que suposen la integracio.

En tots els grups sempre hi ha un ritu que delimita i fa constar la "real" pertinença, algunes vegades més explícit que altres.

\section{Consideracions finals}

En aquest apartat tractarem una sèrie de punts que pretenen obrir debat, punts referits als grups religiosos i al perfil dels membres d'aquests col.lectius. En primer lloc, cal preguntar-nos sobre l'existència d'un perfil pre-sectari i, en segon lloc, quina mena d'empatia existeix entre el grup i els seus membres. Preguntes del tipus si hi ha la possibilitat que una mestressa de casa es converteixi als Hare Krisna, o és més probable que es faci Testimoni de Jehovà, o si un ateu practicant tindrà més afinitat per Gnosis o per l'Opus Dei, serien les adequades per copsar els indicadors que porten a una determinada conversió i que actuaran com a premisses a l'hora d'intentar establir un perfil sòcio-cultural d'individu religiós.

Aquests individus es nodreixen d'ofertes espirituals o físiques. Segons què busqui l'individu es decantarà per un o altre credo: si hom té un problema d'esquena, pot anar a Raschimura a practicar ioga i, si dubta sobre el més enllà, pot acudir als TJ i li donaran la solució. Generalitzant podem dir que cada associació religiosa té un tipus de públic que depèn de la seva oferta. No hi ha un únic perfil d'individu religiós vàlid per a qualsevol grup, però existeix un perfil sòcio-cultural particular en cada grup? Una ex-membre de Siddha Ioga ens diu: "el prototipo de gente que hace una carrera, unos estudios, para ayudar a los demás (ATS, metge, treball social, etc.) es mucho más facil que los cojan (les sectes) que a un economista, a uno de empresariales $o$ a un dependiente de almacén (...), ahora que, a los dependientes de almacén, los cogen los testigos de Jehova". Una reflexió una mica precipitada i reduccionista, però no per aixd menys probable, ja que si ens preguntem quantes mestresses de casa hi ha entre els Hare Krisna, possiblement no en trobem cap i si les busquem en els TJ el nombre serà més elevat. Per què?: perquè el model que segueixen els TJ respon a la tradicionalitat de la famnlia. Per reacció contrària, un individu jove, edat en la qual se sol estar en desacord amb la institució familiar, té més possibilitats d'entrar en els Hare Krisna.

La famflia juga un paper fonamental en la socialització de l'individu. També cal tenir en compte l'educació religiosa que hom ha rebut. D'aquest nucli familiar i d'algunes institucions que l'envolten (escola, església...), en sorgeixen les vocacions oficials: capellans i monges. El fet que el catolicisme sigui la religió més estesa fa que els membres de qualsevol religió, sigui aquesta legítima o no, també provinguin d'una familia catòlica. Hem de dir que no sempre és significativa la creença inculcada per la famnlia, sinó que pot donar origen a diversos credos. Caldria que ens preguntéssim si una família d'ateus convictes pot engendrar un fill carmelita o una filla germana

${ }^{4}$ El ritus consisteix a realitzar els vots: promesa o jurament fet a Déu de mantenir pobresa, castedat i obediència. 
de la Caritat. Sabem que el contrari sol passar.

La desincronització de l'individu amb el nucli familiar pot afavorir la seva demanda d'una alternativa. En alguns casos el grup eri fa la funció o arriba a substituir-la. El subjecte que pateix un quadre depressiu transitori, que es troba en una cruilla (una separació, la mort d'un ésser estimat, etc.) o està malalt, pot efectuar una demanda en un moment concret. Aquests són factors predisponents, però mai determinants.

Una altra consideració que cal fer és la responsabilitat de la conversio: si és el grup qui la provoca mitjançant la seva oferta, o contràriament, és l'individu qui inicia la recerca. La poden iniciar: personalitats "cercadores", individus que troben sense buscar, grups a la recerca de membres i grups que troben membres sense buscar-los. En molts casos poden aparèixer les dues iniciatives al mateix temps: una de l'individu i una del grup.

Comencem per l'individu: per què un subjecte en un moment determinat de la seva vida entra a formar part d'una associació religiosa? Aquest moment pot estar determinat per la trajectòria vital, per un procés personal. Alguns estudiosos afirmen que tot individu és vulnerable d'entrar a formar part d'una secta si el capten en el moment adequat. Però quin és aquest moment adequat? Quan un individu passa per un tràngol personal tendirà a buscar consol o refugi de manera més arbitrària i més a cegues que si no té cap trasbals? I un individu de personalitat vulnerable i que a més és un marginat social tindrà un risc més exponencial? $\mathrm{Hi}$ ha individus aparentment normals des del punt de vista del codi social que es converteixen a un credo que es troba a l'altra banda de la norma? Totes aquestes preguntes ens condueixen a la inexistència de factors determinants. Poden haver-hi elements freqūents o redundants, però mai determinants.

Amb la pregunta "por qué ciertos individuos aceptan integrarse en esos sistemas cúlticos o incluso los buscan cuando no aparecen causas que les fuerzen a ello" (Tornos, 1989/90:32) volem dir que quan una persona passa per un moment determinat, sigui pel període d'adolescència, per una depressió o per una fase d'inseguretat, etc., està més predisposat a buscar on sigui. Tornos fuig de qualsevol tractat psicopatologic apostant per una resposta sociologica: "(...) lo que está ocurriendo con las sectas (...) nos fuerza a reconocer la incapacidad de la sociedad actual para ofrecer a muchos de sus miembros unas imágenes de futuro suficientemente satisfactorias (...). Lo patológico en las sectas sería lo patológico de una cultura resquebrajada (...) y la patologia de unos individuos sometidos a demandas que muy difícilmente pueden satisfacer." (Tornos, Op. cit., 35 ). Així, la societat es converteix en l'única responsable del fenomen religiós. La sociologia va veure l'adhesió a les sectes com una fugida del present, com un refugi a l'anomia social, com una resposta a problemes socials; però també es pot percebre com una excusa utilitzada per donar forma a recerques personals.

La religió canalitza l'anomia social responent a demandes individuals. El sentiment social de decepció s'amaga darrera una visió satisfactòria del microcosmos personal donada per les sectes. Les sectes no són res més que la religió posada al dia, adaptada a la realitat social immediata, i l'única diferència que es troba entre els grups legitimats i els no legitimats és purament circumstancial. Però, com es concreta aquesta "desviacio" cap a les sectes? Uns grups donen l'esquena a la societat, rebutjant-la i percebent-la com a quelcom dolent, però sense fer res per canviar-la (per exemple Raschimura). Altres es presenten com una alternativa, observant la societat com quelcom corrupte, però vivint d'acord amb el seu codi, mostrant el seu desacord i intentant alguna transformació (Testimonis de Jehova). Les diferents manifestacions de la religió poden actuar de cohesionadores d'aquells individus que no accepten el sistema, que responen a una desviació social. Qualsevol d'aquestes visions complauen aquelles persones que han necessitat aferrar-se a alguna cosa per fer més portable la seva existència. Actualment les sectes responen a necessitats psico-socials, servint de consol o lenitiu a aquells subjectes que busquen formes de relació interpersonal, de comunicació satisfactòria.

Hem parlat d'individus que busquen, de persones amb predisposició que abans del contacte amb el grup ja es qüestionaven certs interrogants, de "personalitats cercadores". Però existeix 
l'altra cara de la moneda: aquell individu mancat de problemes físics o metafísics que en establir contacte amb el grup li són suscitats alguns dubtes per a posteriori donar-li les solucions. La creació de necessitats per després poder satisfer-les.

En el camp religiós s'ofereixen tres opcions que solen anar molt lligades: la primera, "servir Déu": grups legitimats o no, que fan de la seva vida una dedicació absoluta i exclusiva a les seves creences. S'ofereixen a Déu mitjançant l'oració i la meditació. Per exemple, Hare Krisna, monges benedictines i en general grups que viuen en comunitat. Podríem dir que són -ho creuen- servents de Déu. La segona opció és "ajudar els altres o el món": grups legitimats o no, on els seus membres dediquen unes hores del dia als altres, oferint-los una ajuda activa. Són grups altruistes, perquè l'epicentre de les seves accions són els altres. La tercera opció és "ajudar-se a ells mateixos": solen ser grups no legitimats, practicants de teràpies alternatives a les tradicionals com l'acupuntura, el ioga o el naturisme (per exemple Raschimura o Dianètica). Aquests darrers grups responen a una demanda actual, mentre que els de les dues primeres opcions fan la funció que sempre ha estat en mans de la religio: déu i el proisme. Tot i així, cadascuna disposa del seu públic.

Hem vist que les associacions religioses responen a una demanda psico-social solucionant diferents necessitats, siguin de pertinença, d'inseguretat, d'espiritualitat, etc., però necessitats que responen a un present. A les darreres dècades la religió oficial ha anat perdent credibilitat $i$ ha anat quedant obsoleta: mentre la societat ha evolucionat, aquella no ho ha fet. Com a resposta a l'estancament han sorgit, paral-lelament a la religió convencional, grups de substitució adaptats a les necessitats del moment que faran la seva funcio. Llavors, entre uns grups i uns altres no es pot parlar de diferències que no siguin temporals; si és així totes les sectes s'acabaran normalitzant. Però sigui quina sigui l'entitat normalitzada, la funció sempiterna de totes les religions no deixarà de ser la de dotar de sentit a la vida, una vida que, com diu Cioran, només mitjançant l'engany $\mathrm{i}$ el miratge es pot fer més suportable.

\section{BIBLIOGRAFIA}

CLARK, J.G./LANGONE, M.D./SCHECTER, R.E./DALY, R.C.

1981 Conversion to Dangerous Cults: Theory, Research and Treatment. Boston, Center of Destructive Cultism, a CARMONA, A./MARCO, M./PAZ, J./SANCHEZ, J. (1989), "Cambio de actitud y comunicación persuasiva: Claves para comprender los procesos de captación y conversión a sectas", Apuntes de psicología. Revista del Colegio Oficial de Psicólogos Andalucía Occidental, $\mathrm{n}^{\circ}$ 28-29.

RODRIGUEZ, A.

1992 El lavado de cerebro. Barcelona, Ed. Boixareu Universitaria.

TORNOS, A.

1989/90 "Psicopatología de la sectas religiosas", a Memoria académica. Madrid, Instituto de Fe y Secularidad. 


\section{ANNEX}

\section{Dona, 38 anys, ex-membre de Gnosis}

Es la gran de set germans. El seu pare ha treballat en diferents empreses i la seva mare sempre ha estat funcionària. De petita va estudiar a les franciscanes $\mathrm{i}$ va ser escolta durant vuit o nou anys. Als 13 anys arriba a Tarragona i estudia a les Teresianes i té contacte amb les "Hijas de Marfa o Legión de Maria", amb les quals programaven excursions.

De pares catolics, a partir dels 14 anys deixa d'assistir a missa amb la famnlia i de tocar la guitarra amb un grup a l'església. Als 15 anys va amb unes amigues a visitar un noviciat de teresianes a Tortosa, a fer exercicis espirituals $\mathrm{i}$ a descansar. En aquest moment pensa que li hauria agradat una vida tranquil-la $\mathrm{i}$ dedicada a pensar, però només s'hi està quatre dies ja que no li atrauen tantes normes. Amb els anys desconfiarà de les monges. d'art.

Estudia química a la Laboral, passa un parell d'anys estudiant Graduat Social i dos anys més a l'escola

Als 16 anys s'enamora; abandona els estudis i es posa a treballar. Als 20 anys es casa, un any després té una nena $\mathrm{i}$ al següent, un nen. Als 28 abandona el seu marit; ell es queda amb els fills, pero diariament els veu. Passat un any li deixa els nens a ella. Als 30 anys treballa d'ajudant de cuina i té un bar.

Es defineix com una persona molt radical amb esperit de líder. Es militant d'un partit radical d'esquerres i forma part d'una comissio pro-avortament.

El seu germà li regala un llibre sobre el tarot, comença a investigar sobre el tema $i$ arriba a l'astrologia on es queda "enganxada". N'estudia pel seu compte i es relaciona amb persones que també hi estan interessades.

Un dia ensopega amb un anunci que oferia classes d'astrologia, tarot, cabala, ciències ocultes i que prové de Gnosis. Assisteix a la primera xerrada i continua anant-hi un cop per setmana. Pren apunts, estudia a casa seva i fa exàmens per pujar de nivell.

Participa en excursions -en alguna d'aquestes l'acompanyen els seus fills- on fan meditacio, estudien les plantes $\mathrm{i}$ altres pràctiques. Assisteix a un congrés gnòstic d'àmbit mundial.

$\mathrm{Va}$ arribar un moment en què no podia assimilar les ensenyances, en què li faltava temps i va optar per deixar d'assistir a les classes.

El contacte amb Gnosis va canviar la seva vida: la va ajudar a conèixer-se ella mateixa, a ésser ella, a interioritzar eliminant allo afegit que tenia com a persona, a trobar la seva veritable essència. Ara és conscient de qui és i del que fa en cada moment. Es considera més benevolent amb el món ja que ha aconseguit ser-ho amb ella mateixa.

Encara que actualment no forma part del grup gnòstic, es considera gnðstica. Continua estudiant astrologia en un centre

on paga 6.000 ptes. al mes per una hora setmanal. A casa seva estudia un parell d'hores diàries abans de dormir, "si no estudio astrologia no me puedo dormir; es como una droga, la astrología." També fa pràctiques de meditacio pel seu compte un parell de dies a la setmana.

No sabem en quin moment va ésser que va tenir alguna relació amb la droga, "me he metido de todo por probar todo, no hubo nada que me atrajera especialmente, pero no me he saltado nada".

\section{Dona, 48 anys, ex-membre de Gnosis de Carf}

Casada amb dos fills. Té una germana 19 anys més petita que ella a qui sempre l'han atret els temes relacionats amb l'esoterisme i l'astrologia; ella també els tenia certa simpatia.

La seva germana i una amiga, després de veure un anunci sobre un curs d'esoterisme fet per Gnosis de Carf, van convèncer-la per assistir-ne a la presentació a una escola de capellans. Els van dir que eren uns cursos interessants per a la millora de la gent.

Va començar a anar-hi una hora, un cop per setmana. La seva germana i l'amiga ho van deixar per motius d'estudis, però ella va continuar (pensava "sempre aprendrds algo aqu" ).

En trobar-se sola va establir més contacte amb la gent. El professor li deia que ella era una persona molt interessant $\mathbf{i}$ que "servia molt". Va continuar assistint-hi dos cops per setmana $\mathbf{i}$, més endavant, tres dies setmanals.

A cada classe els donaven unes anotacions amb la temàtica a tractar i de tant en tant realitzaven proves per ascendir de nivell.

Practicaven ioga, exercicis de respiració, tècniques de viatge astral; els ensenyaven el mitja per lliurar-se de les coses materials $\mathbf{i}$ del lligam del cos per poder assolir un estat divi. Els membres eren animats a realitzar 
aquestes pràctiques a les seves cases.

Mitjançant el viatge astral, podien arribar a dominar el món i alguns gnòstics podien levitar. Ela va intentar fer un viatge astral a casa seva, pero "me va pegar una sotragada el cos, que vaig dir: mai més!".

Es trobava a l'espera de poder realitzar aquestes pràctiques; els deien que algun dia els donarien la "clau": "jo estava amb aquell dubte $i$ aquella curiositat $i \mathrm{em}$ deien podia ser més que els altres, que podria dominar la gent, que $n$ 'estava capacitada $i$ que dintre de poc entraria a formar part d'aquelles persones seleccionades. Aquesta cosa era lo que em feia a mi estar alla*. L'espera de la revelació de veritats, de la solució de la vida i creure que podia arribar a ésser semi-déu era el que la mantenia a Gnosis.

El líder li deia: "Muchos éramos los llamados, pero pocos los escogidos". Se sentia molt atreta pel professor, seduïda; afirma que aquest exercia una mena de poder mental sobre els alumnes.

El seu marit la va acompanyar a una excursió a Montserrat (la muntanya màgica), on es van trobar gnòstics de diferents pobles. Alli van fer practiques i els van parlar del fundador.

Arran d'aquesta sortida, el seu espòs visita M. Rosa Boladeras (AIS, Assessorament i Informació sobre Sectes), la qual li diu: "Corrent, que vingui perque si no la perdrem". A la qual ella ara hi diu: "A mi, quan me va cridar la $M$. Rosa i $m$ 'ho va explicar tot, tal com ho veia ella, vajal no em va costar gens de veure-ho clar (...). Si no arriba a anar el meu marit jo ara estaria enganxant cartells pel carrer, o una cosa pitjor".

Abandona el grup i actualment té relació amb la Societat Teosঠfica, de la qual li ha dit la M. Rosa Boladeras que no és una secta.

3. Home, 28 anys, ex-membre d'AGEACAC (Asociación Gnóstica de Estudios de Antropología y Ciencia)

Procedent d'una familia de classe mitjana, el seu pare es treballador d'una empresa de seda $i$ la seva mare mestressa de casa. Considera la seva famflia ben normal, on el pare sempre ha lluitat per donar-ho tot als fills, "excepto un poco de afecto". La religio no ha ocupat mai una part important a casa seva; afirma que han seguit les línies del catolicisme més per tradicio que per devocio; va fer la comunio, assistien a casaments, anava a missa de tant en tant, etc. De totes maneres sempre ha cregut en Déu.

Es considera una persona amotllable a tot, a qui li agrada tenir amics i anar de discoteques de tant en tant.

Des de sempre l'han atret els temes relacionats amb l'ocultisme, aixf com el tarot i l'astrologia. To aixd percebut com una forma de buscar el perquè de les coses i del més enlla.

Abans de conèixer el grup practicava ioga en un gimnàs per tenir elasticitat.

El primer contacte amb el grup el té cap als 25 anys. La noia amb qui sortia va morir d'un atac d'asma. Coneix una altra noia que tenia una germana que estudiava psicologia $\mathrm{i}$ acupuntura $\mathrm{i}$ que combregava amb AGEACAC des de feia cinc anys. En sortir amb aquesta noia i per influència de la seva germana, la qual els deixava llibres gnòstics i els parlava molt del grup, van començar a assistir a classes un cop per setmana.

En el centre els explicaven la lliç6 del dia i en acabar hi havia preguntes $i$ un col-loqui sobre el tema tractat. L'atreia molt el tema dels somnis i la seva relació amb la vida real; més endavant va iniciar-se en la meditació $i$ en els viatges astrals. Els donen a entendre que "nosotros estábamos alli y que hablamos coincidido alll por una razón (...) porque nos habla tocado el reunirnos alll y seguir al gran maestro Samael".

Aquesta relació d'un dia a la setmana el porta a introduir elements gnostics a la seva vida personal: insonoritza una habitació de casa seva per practicar "mantras", procura seguir les normes sexuals del grup de cara a plantejar-se un matrimoni $\mathrm{i}$ un futur gnঠstic, pero li costa molt assumir aquests hàbits, "(...) eso de aguavtarte la eyaculación lo tenía bastante asumido, (...) hay que ser mugy consciente y trabajar mucho para llezar a mantener una serie de eyaculaciones sin llegar a cyacular. Entonces, claro, como toda persona, llega un momento que se escapa (...). Y, bueno, ella se lo tomaba un poco más fuerte que yo".

Fa proves o exàmens interns per pujar de nivell. La seva xicota li regala una medalla beneỉda que ja pensava comprar, el "tetragramaton", símbol dels gnðstics. gnðstics.

Mai va participar en cap excursio a Montserrat ni en cap convivència, activitats que acostumen a fer els

Arran d'un programa de televisió, els seus pares descobreixen que el seu fill esta essent víctima d'una secta. Es posen en contacte amb AIS i "luego mira, es una secta, pues mira, ahl se queda, no me interesa". També va haver d'abandonar la noia, ja que ella no volia deixar el grup.

Considera que tant AIS com una vident el van ajudar molt en la decisió. Aquesta li va dir que els gnòstics treballen amb energia negativa i que mitjançant el tetragràmaton li feien arribar aquesta energia. La vident el va lliurar d'aquesta, "me dijo que me deshiciera de la medalla, (...) que la tuviese 24 horas en sal para quemarla luego en alcohol y eso hice". Les xerrades amb AIS li plantegen molts dubtes i contrarietats. 
una filla. Quatre anys després se separa i se'n va a viure sol, buscant una recerca espiritual: "(...) como si buscara algo más que no esa vida tan monótona de trabajar, ir a casa, en fin, salir por las noches a tomar unas copas... una vida bastante normal, pero para mi muy vacia".

Vol canviar de vida i se'n va a viure a Barcelona amb els seus pares. Continua cercant espiritualitat i meditant sobre la seva vida. Deixa de beure, de fumar i busca amistats espirituals; mira de connectar amb grups d'aquest caire que s'anuncien al diari. Busca en llibres de meditació.

Es fa vegetarià, alimentació que el fa sentir millor; a partir d'aqui comença a investigar sobre naturisme i macrobiotica, sobre medicina natural, etc.

Aquesta recerca el condueix a diferents grups. Ho vol provar i experimentar tot: practica tai-chi, sufisme (meditació mitjançant la dansa), passa tres anys a Gnosis, fa estades de cap de setmana a Arco Iris i meditació activa amb Rajneesch.

Va estar una temporada tastant diferents drogues: LSD, cocaina, heroîna, etc.

Durant una època viu de fer massatges; assisteix a Suĩssa a un congrés de macrobiotica on també es tractaven els massatges. En allí coneix Brahma Kumaris: la seva filla, la qual el va acompanyar, coneix un bome cristia molt admirador de BK. Ambdós es coneixen i intercanvien opinions: aquell li parla de BK i del ioga que practicaven. Quan arriben a Barcelona, aquest home el convida a un sopar macrobiotic i li continua parlant de BK de manera fascinant. Ell s'anima i l'invita a prendre te al centre de BK on queda meravellat. S'entusiasma de tal manera que s'apunta a un curs de meditació. Cada vegada hi va tenint més relacio,, l'atrau molt la seva forma de vida: celibat, vegetarianisme, aixecar-se aviat $\mathbf{i}$ el ioga, entre altres matèries. Dos anys abans de conèixer BK ja havia optat per no tenir relacions sexuals, per deixar de fumar, de beure i de consumir cap altra droga. També $s$ 'havia decidit pel vegetarianisme. Diu que amb aquesta normativa s'estalvia energia i es purifica la ment; aquesta energia després es pot dedicar a la creativitat.

Cada vegada li agrada més anar al centre BK, hi assisteix a diari; a voltes la seva filla l'acompanya.

\section{Home, 33 anys, membre de Testimonis de Jehova}

De famflia mitjana, el seu pare treballava al camp. Ell fa 17 anys que treballa d'enguixador pel seu compte, mai no li ha agradat deprendre de cap superior.

Cap als 13 anys comença a sortir de nit, als 15 fuma porros, als 17 continua amb l'haixix, anfetamines i "bustain". Es compra una moto i abandona una mica el món de la droga, per passar-se al món del motor. Al cap d'un temps ven la moto i marxa a la "mili". L'envien a la muntanya a causa de la seva indisciplina. Alli comença a valorar $\mathrm{i}$ a estimar la natura, alhora que s'introdueix més a fons en la droga. Passa vuit mesos desconnectat del món urbà.

En acabar el servei militar torna amb els amics d'abans; els atrau molt la natura $\mathbf{i}$ fan sortides a la muntanya. Adquireix un tros de terra i la deixa a uns amics que tenien un filosofia de vida mig hippy, "deien que el món $i$ que la terra era de tots". Aquesta ideologia el fascina i diu "si tot el món és nostre, anem a voltar" i se'n va a viure a Eivissa.

Alli continua amb la droga (LSD, heroina...), on intenta comprendre i entendre la vida per mitja de la droga. Observa i practica la vida hippy, viu en un vaixell amb altres persones, es passen el dia tocant la guitarra. Té amics que venen droga $i$ es fica en alguns embolics de tràfic. El detè la policia. Passa temporades vivint al carrer, pren molt LSD. Es camell.

A Eivissa coneix una noia del seu mateix poble i se n'enamora. Per separat tornen a la península. Més endavant es casen.

A tots dos els agrada l'astrologia. Freqũenten un bar on un amic els parla de temes bíblics. Ells s'interessen $\mathbf{i}$ acaben acudint a un estudi biblic (des d'aquest dia, no han deixat d'anar-hi, ja que alla van trobar la veritat i l'origen de la vida). Des del primer dia d'anar al Salón del Reino es van adonar que era allo el que realment buscaven.

Ara busca la terra feta un paradís sota el Regne de Déu.

Abans de conèixer els TJ, eren unes persones molt indisciplinades $\mathrm{i}$ la Biblia els va donar "disciplina amb amor": en un mes van deixar de fumar, van canviar d'ambient i es van apartar una mica de tot el que anteriorment els envoltava. "Primer es necessita coneixement del que es diu $i$ després una conducta justa, apartar-se de tot el que implica el sistema que hi ha".

Es consideren esclaus de Déu, fan proselitisme de manera molt organitzada. Reconeixen que la seva vida ha canviat un $100 \%$ : ara tenen una esperança $i$ coneixen la veritat, saben que tindran una altra vida millor, que Déu transformarà la terra, "aquest fet anima a la gent a tenir fe".

Basen totes les seves afirmacions o respostes en la Biblia, la qual corrobora tot el que diuen. 
7. Home, 33 anys, membre de Testimonis de Jehovà

Prové d'una familia d'immigrants. De tradició catòlica, va fer la comunió i es va confirmar, però no són el que se'n diu beats.

Actualment treballa de paleta i està casat amb una dona, també TJ.

El primer contacte el té als 18 anys mitjançant un amic que el convida a un estudi brblic. Hi assisteix per curiositat: a casa d'un particular li expliquen els proposits brblics mitjançant el llibre La verdad, llibre de preguntes i respostes que contesta, "aquelles preguntes que l'home es pot fer a llarg de la seva vida". Continua realitzant l'estudi un cop per setmana i troba totes les respostes en la Biblia.

Després de sis o set mesos ja ha adquirit les veritats bàsiques i es bateja. Ha decidit dedicar la seva vida a Déu i col-laborar a estendre el coneixement de Jehovà.

Des de la conversió afirma viure amb proposit $i$ esperança. Saber que hi ha vida eterna i que el mal de la terra s'acabarà dóna un sentit a la seva vida que abans no tenia: abans tot es reduīa a menjar, dormir... En conc̀ixer els TJ va donar un gir de 180 graus i la seva vida es va convertir en alegria i felicitat en saber que tenia vida eterna.

\section{Dona, 35 anys, membre de Testimonis de Jehovà}

De petita li agradava anar a l'església, sentia necessitat de creure i de parlar amb Déu. Sempre ha tingut un fort sentit de religiositat $i$ parteix de la base que tothom té alguna mena d'inclinació a adorar alguna cosa.

Fins als 18 anys pertany a una associació de joves catolics. De més gran té relació amb sindicats polítics, "he sido una persona que siempre he intentado buscar algo y pensaba que en la politica lo encontraria".

La seva feina de dependenta la porta a conèixer una companya membre de $\mathrm{TJ}, \mathrm{i}$ a partir d'aquest contacte comença a investigar en la Bßblia i sent que la religió catolica I'ha enganyada. Assisteix a una escola biblica dels TJ i continua investigant a través de llibres que li ofereixen. TÉ 16 o 17 anys.

Passa sis mesos estudiant les "veritats basiques" i anant a reunions; amb el temps va veient que tot allo que diuen els llibres $t s$ cert.

A partir del baptisme ja no pertany a ella mateixa, sinó a Jehovà. Ha millorat com a persona i basa la seva vida en un ordre teocràtic $i$ en els principis biblics.

Si els TJ actuen d'acord amb aquests principis viuran sempre. També han de fer veure a les altres persones la veritat de la Biblia per ajudar-les a la salvació.

Es considera súbdita d'un nou govern que crearà Jehovà en un futur, on no existiran ni la malaltia ni la mort.

Actualment, resta a l'espera de la fi del món i a l'arribada del Regne de Déu a la terra.

\section{Home, 37 anys, ex-membre carmelita}

De famflia d'agricultors, de petit ajudava a les tasques del camp. La seva mare i la seva àvia eren religioses, però no més que qualsevol altra dona d'aquella època: eren creients $i$ anaven a missa. De petit feia d'escolà al seu poble.

El seu germà menor va néixer en un hospital de monges i en una visita que va fa fer una monja el portà a veure un seminari diocesà. Li va agradar tant que va parlar amb el vicari del seu poble per mirar d'entrar-hi, però no va poder perquè el seminari era molt selectiu.

Abans d'acabar el curs escolar va passar un frare carmelita per l'escola. Aquest anava recollint vocacions pels pobles. Va quedar captivat pel seminari i demana a casa seva si li deixarien anar.

Als nou anys ingressa al seminari carmelita: els primers dos anys no torna mai a casa. Troba moltes exigències i moltes obligacions: menjar en silenci, dutxar-se amb aigua freda...

L'expulsen del seminari en tres ocasions per indisciplinat.

Als 15 anys marxa a Alemanya amb dos companys, també carmelites, un dels quals ja havia fet els vots. Treballen d'il-legals. Volen viure com a joves, no com a creients, tot $\mathrm{i}$ que anaven a missa, feien pregàries $\mathrm{i}$ litúrgies. Al cap d'una temporada tornen i construeixen escoles per a immigrants, per als pobres i per a la joventut marginada.

Als 19 anys fa el noviciat, on dedica 24 hores al servei de Déu. Passa tot un any meditant sobre la vida religiosa.

Fa els vots i marxa a Roma, on tindrà molta relació amb el Vaticà i amb una noia amb qui tindrà un inici de relació de parella.

Arriba un moment en què pensa que el que fa com a frare també ho pot fer com a seglar $\mathrm{i}$ no es troba 
útil dins els carmelites. També es qủestiona algunes postures de l'Església, no així la creença en Déu.

Als 26 anys abandona l'orde $i$ es casa; alguns companys carmelites el rebutgen.

\section{Home, 45 anys, ex-germà de La Salle}

De petit feia de pastor a casa seva perquè el seu pare es dedicava al camp. Quan té set o vuit anys passa pel seu poble un reclutador vocacional que l'entusiasma; ho veu com una sortida per poder estudiar, ja que els membres d'aquest orde eren mestres. Als 11 anys entra al seminari on cursarà estudis. Als 16 anys entra al noviciat on estudia la regla de l'Institut dels germans de les escoles cristianes, on passa dos anys. Fa vots per un any, com a prova.

Tres anys després acaba el batxillerat superior i després estudia Magisteri. Acaba l'any 1968, als 20 anys.

L'envien d'un lloc cap a un altre, porta una vida molt estricta, sense vacances $\mathbf{i}$ amb molt de silesci.

Més tard estudia a Tarragona i a Salamanca, on se li obre un altre món. Als 26 anys pronuncia els vots perpetus. El fan treballar molt, se sent tan explotat que no té temps ni per a temptacions. Als $30-31$ anys abandona l'orde "ja que per esser mestre no em calien els vots perpetus".

\section{1.- Home, 22 anys, ex-membre de Moon.}

De pares catolics no practicants, estudia en una escola catolica.

Mai no ha tingut molts amics a causa del seu caracter introvertit: d'adolescent no acostumava a sortir gaire i percebia les diversions com quelcom superficial.

Des de sempre s'ha plantejat preguntes del tipus "d'on venim $i$ a on anem" $i$ ha tingut una actitud de recerca interior que observa com quelcom innat.

Actualment es defineix com a creient del missatge de Jesús i confia en la Biblia.

Als 17 anys té el primer contacte amb Moon. Està travessant un mal moment, sense amics, es trobe sol i deprimit. Va ésser una trobada fortuita, al carrer, on hi havia un grup de joves que venien llibres. S'bi va acostar i li van dir: "Somos cristianos, estamos vendiendo libros, vente con nosotros a pasar un buen rato de amistad y compafierismo". Li va atraure que busquessin la veritat i que es preocupessin pels problemes. d'actualitat, de la vida, de la mort i del més enlla.

Comença a col-laborar en les seves activitats, fan classes, veuen pel-lícules, canten... Perd el fonamental va ser la comprensió i la confiança que troba en el grup, un ambient amable que en aquell moment necessitava. Observa la religió en un pla secundari, li atreia la Biblia, però no aprofundia en la teoria, tot i que cada vegada va sentint més curiositat per la recerca de la veritat en la Biblia.

No té un contacte diari amb Moon, sinó que són trobades a intervals ja que el grup solia canviar de lloc i de vegades solia desaparèixer una temporada.

Moon tenia relació amb la medicina natural, posseia una botiga d'herbes on treballaven els membres més antics.

Adoraven un Messies que equiparaven amb Déu. Ell una vegada va arribar a veure visions: el Messies pel carrer envoltat per un núvol.

Percep els de fora del grup com a kssers perduts, propers a Satanàs; va perdent el contacte amb la seva famflia, a qui qualifica com a victimes de Satan.

Els seus pares s'oposen que vagi a passar un cap de setmana amb Moon i es posen en contacte amb ProJoventut. En assabentar-se que Moon era una secta, abandona el grup amb el qual havia simpatitzat duran tres anys.

\section{Home, $\mathbf{3 0}$ anys, ex-membre de Rachimura}

Als 17 anys estudia $\mathrm{i}$ treballa, surt amb els amics a lligar. Li costa molt esforç compaginar treball $\mathrm{i}$ estudis, té algun problema de cansament $\mathbf{i}$ un company li recomana el ioga com a teràpia de relaxació.

Comença a assistir a classes de ioga en un centre on també es practica acupuntura, medicina naturista, música, karate, etc. $i$ on el seu germà anava a sessions d'acupuntura.

En el moment del primer contacte confirma no tenir cap problema de tipus existencial, no es qũesticeava la religió ni es feia preguntes de tipus transcendent.

Dos amics marxen a viure fora $i$ es troba una mica sol $i$ aillat.

S'aboca de ple en les classes de ioga i li apareix tota una filosofia darrera les practiques. El professor li planteja alguns dilemes de caire metafísic i li dóna solucions mitjançant la filosofia del grup. Arriba un monent 
en què es pregunta si tot el que aquell li diu es veritat, què fa ell perdent el temps estudiant i treballant?

Comença a llegir llibres d'esoterisme que connecten amb la filosofia del mestre i veu en el ioga un camí de perfecció cap a Déu. Fa meditació a casa.seva i descobreix moltes experiències físiques. Li donen un mantra secret que no pot revelar a ningú si no vol que se li torni en contra.

Assisteix a un curs intensiu del grup: una setmana amb dieta d'arròs bullit, meditant sobre Déu, la reencarnació, la vida, l'ànima, etc. i criticant la societat de consum. Barregen temes biblics, taoistes i budistes. Aquesta vivència li representa una experiència mística molt forta on es plantejarà la raó de la seva vida.

En acabar el curs ingressa en el grup i talla la relació amb els seus pares. Passa a tenir metes espirituals, rebutja tot allo material i es revolta contra allo socialment establert. Diferencia el seu món del món de "fora" i veu en el seu mestre el caml cap a déu.

Abans d'efectuar la veritable conversió haurà de passar unes proves que consistiran a treballar intensivament durant dos mesos, seguir una dieta molt drastica a base d'arròs i poma i acceptar tota una sèrie de castigs, com dutxes d'aigua freda, en cas de transgredir les normes. El fonamental es seguir les ensenyances. Si estaven malalts, per exemple, es curaven seguint les ensenyances: amb pau espiritual no podia haver-hi malaltia. El grup seleccionava la televisió i el cinema que podien veure, el sexe era considerat tabú i el desig era el mal.

Veneraven al mestre com un Déu i el consideraven el pare de tots, la màxima era donar la vida per ell. La intimitat no existia: el mestre els obligava a tenir relacions sexuals en grup amb els ulls tapats. Els diversos membres tenien fills que eren considerats fills del mestre.

Abandona el grup quan porten al metge una nena $i$ aquest els diu que està mal nodrida. Aquest fet fa que ell comenci a dubtar de les ensenyances. 